\title{
AQUISIÇÃO DA RETRAÇÃO ACENTUAL DO INGLÊS POR FALANTES DE PORTUGUÊS BRASILEIRO ${ }^{1}$
}

\author{
Carina FRAGOZO* \\ Raquel Santana SANTOS ${ }^{* *}$
}

- RESUMO: Este artigo discute a aquisição da regra de retração do acento do inglês por falantes do português brasileiro, lançando luzes sobre a influência da L1 e do ensino na aquisição de uma L2. Foi aplicado um experimento no qual 37 falantes nativos e não-nativos de inglês produziram as mesmas palavras isoladamente, em contexto de choque acentual e em contexto sem choque acentual, de modo que se pudesse observar a produtividade desse fenômeno. Os resultados encontrados mostram que a retração ocorreu em proporções semelhantes em contextos com e sem choque acentual e que os aprendizes de nível avançado se aproximaram bastante da taxa de aplicação dos nativos. Também se observou que palavras terminadas em obstruinte não favoreceram a aplicação da regra enquanto palavras terminadas em vogal longa ou nasal favoreceram, o que evidencia que a estrutura silábica e o inventário segmental da L1 afetam os resultados da $\mathrm{L} 2$.

- PALAVRAS-CHAVE: Aquisição de segunda língua. Retração acentual. Inglês. Português brasileiro. Aquisição fonológica.

\section{Introdução}

Desde o início, a pesquisa em Aquisição de Segunda Língua (L2) tem buscado descrever possíveis semelhanças e diferenças entre a representação da gramática da língua materna (L1) e a gramática não-nativa. Se, por um lado, considerarmos o alvo a ser alcançado no processo de aquisição, as diferenças não são muitas: em ambos os casos, o objetivo é chegar a um sistema linguístico que corresponde ao input recebido, de modo que o aprendiz consiga falar e compreender a língua-alvo. Por outro lado, aprendizes de L2 normalmente precisam de algum tipo de instrução e levam muito

\footnotetext{
* Universidade de São Paulo (USP), Faculdade de Filosofia, Letras e Ciências Humanas, São Paulo - SP - Brasil. cfragozo@gmail.com. ORCID: 0000-0002-8582-8469.

*** Universidade de São Paulo (USP), Faculdade de Filosofia, Letras e Ciências Humanas, São Paulo - SP - Brasil. raquelss@usp.br. ORCID: 0000-0002-0277-7994.

1 Uma versão anterior deste trabalho foi defendida em Fragozo (2017). Agradecemos aos participantes da banca de doutorado, aos participantes de eventos onde este trabalho foi apresentado e aos dois pareceristas anônimos pelos comentários e discussão do texto e os eximimos de todos os problemas remanescentes.
} 
mais tempo para atingir um domínio básico da língua-alvo. Além disso, ainda que o alvo a ser alcançado seja o mesmo, o estágio final da aquisição de L2 é, na maioria dos casos, muito diferente daquele adquirido na L1.

A transferência de aspectos da língua materna para a língua-alvo é considerada uma influência importante durante o processo de aquisição de língua estrangeira. $\mathrm{O}$ conceito de transferência foi herdado da pesquisa behaviorista, segundo a qual o aprendizado de uma tarefa " $A$ " afetaria o aprendizado de uma tarefa "B", numa relação de "aprendizado cumulativo". Essa transferência pode ser positiva (também chamada de facilitação), quando resulta em uma produção correta, ou negativa (também conhecida como interferência), quando resulta em uma produção diferente do falar nativo (GASS; SELINKER, 2008). Segundo Major (2001), o papel da transferência na aquisição de L2 já era mencionado em Trubetskoy (1939), mas foram os trabalhos de Fries (1945), Weinreich (1953) e Lado (1957) que deram início ao desenvolvimento da Hipótese da Análise Contrastiva (Contrastive Analysis Hypothesis). Segundo essa hipótese, os aspectos da L2 que são parecidos com a L1 seriam mais fáceis de adquirir do que os que são diferentes. Esses trabalhos tentavam prever e explicar os erros de pronúncia cometidos pelos aprendizes de L2. Entretanto, resultados como os de Selinker (1972) mostraram que nem todos os erros cometidos por aprendizes de L2 eram resultado de uma transferência da L1 para a língua-alvo, pois a transferência era apenas um dos fatores influenciando a produção do aprendiz.

Segundo autores como Broselow e Kang (2013), há dois problemas em se afirmar que os erros cometidos por aprendizes de L2 são causados exclusivamente por transferência. O primeiro é que, em muitos casos, determinadas estruturas que não existem na L1 são mais facilmente adquiridas do que outras também inexistentes na L1, independentemente das características da L1 ou da L2. O segundo problema é que, apesar de a fala dos aprendizes de L2 apresentar padrões coerentes e sistemáticos, esses padrões são muitas vezes diferentes daqueles na L1 ou na L2. Segundo as autoras, esses casos são influenciados por fatores universais como a marcação, em que fenômenos marcados são mais complexos e incomuns nas línguas do mundo do que os não marcados. A marcação, construto teórico proposto inicialmente por Trubetzkoy (1939), influenciou grande parte dos estudos em aquisição fonológica de L1 e passou a ser utilizado na aquisição de L2 a partir de Eckman (1977), que propôs a Hipótese da Marcação Diferencial (Markedness Differential Hypothesis), cujo objetivo era identificar o grau de dificuldade na aquisição de determinada propriedade da L2 com base na L1. Segundo esta hipótese, as áreas da língua-alvo que diferem da língua materna e são mais marcadas do que na L1 serão mais difíceis; o grau relativo de dificuldade das áreas da língua-alvo que são mais marcadas do que na L1 corresponderá ao grau relativo de marcação; as áreas da língua-alvo que diferem da língua materna, mas que não são mais marcadas do que aquelas na L1, não serão difíceis. (ECKMAN, 1977). Em suma, fenômenos não marcados são adquiridos mais facilmente do que os marcados, ainda que nenhum deles ocorra na L1, o que pode ser entendido como resultado de uma preferência universal por estruturas menos marcadas. 
Além da marcação, graus de similaridade/dissimilaridade são aspectos relevantes no que diz respeito à transferência da L1 para a L2. Diferentemente das previsões da Hipótese da Análise Contrastiva, Major (2001) propõe que os sons que forem similares na L1 e na L2 são mais difíceis de serem adquiridos do que aqueles que são dissimilares, porque a similaridade dificultaria a tarefa do aprendiz de desenvolver novas categorias fonológicas para sons tão semelhantes nas duas línguas. Nesses casos, a tendência é que o aprendiz aplique o padrão da L1 em vez de desenvolver a categoria correspondente da L2.

A questão da similaridade na percepção de sons não nativos também foi apontada em Flege (1995) que, através do Speech Learning Model, propõe ser possível prever a dificuldade na aquisição de sons não-nativos de acordo com o grau de similaridade entre os sons da L1 e da L2. O modelo prevê que sons da L2 idênticos aos da L1 serão adquiridos com facilidade, sons da L2 que são muito diferentes da L1 serão adquiridos com um pouco menos de facilidade, e os sons da L2 que são parecidos, mas não são idênticos aos da L1, serão os mais difíceis de serem adquiridos. Em outras palavras, é necessário um certo grau de dissimilaridade entre os sons da L1 e os da língua-alvo para que o aprendiz seja capaz de perceber o contraste já que, nos casos em que os sons são parecidos, mas não idênticos, o aprendiz tende a processar o som da L2 numa categoria perceptual da L1.

Não se pode negar, portanto, o papel da língua materna sobre a aquisição de segunda língua, sobretudo quando consideramos a aquisição de falantes adultos. Diferentemente do que a visão behaviorista previa, entretanto, observa-se que a transferência da L1 não ocorre de forma automática e mecânica, mas depende de diversos fatores linguísticos e não linguísticos ${ }^{2}$ que determinam como ou quando essa transferência tende a ocorrer. Com este artigo, pretendemos trazer mais dados para a discussão, olhando para a aquisição de um processo muito similar no inglês e no português brasileiro (doravante PB), a retração acentual (stress shift).

Para tanto, este artigo organiza-se da seguinte maneira: inicialmente tratamos da regra de retração acentual, e em seguida descrevemos como esta regra ocorre no inglês, no PB, e o (pouco) que se sabe sobre aquisição da retração acentual do inglês por falantes do PB. Apresentamos então nossa metodologia de estudo, os resultados, e por fim a discussão e considerações finais.

\section{A regra retração de acento}

Para se discutir a retração acentual, é necessário primeiro caracterizar o que seja acento lexical, já que nas duas línguas a retração ocorre quando há um choque de

\footnotetext{
Diversos estudos tratam também de fatores não-linguísticos como a aptidão (GASS; SELINKER, 2008; CARROLL, 1989, entre outros); a quantidade do input (CORDER, 1967), a qualidade do input (FERGUSON, 1971; KRASHEN, 1981; MATTOS, 2000; GASS; SELINKER, 2008 entre outros) e fatores emocionais como motivação, baixa confiança e ansiedade (KRASHEN, 1981). No entanto, são ainda tema de debate, já que demonstrar a relação entre eles e a aquisição não é algo simples.
} 
acentos primários. No que concerne à produção, em termos articulatórios, o acento de uma sílaba depende de mais energia muscular e mais atividade respiratória do que se observa em uma sílaba átona. No que diz respeito à percepção, as sílabas acentuadas são reconhecidas como tais por serem mais proeminentes do que as sílabas átonas. $\mathrm{O}$ acento é, portanto, visto como uma propriedade relacional, pois uma sílaba só pode ser considerada acentuada se comparada a outras sílabas não acentuadas.

Acusticamente, os quatro principais correlatos do acento são a frequência fundamental (F0 ou pitch), a duração, a intensidade e, menos comumente, os formantes, e as línguas podem apresentar comportamentos diferentes com relação a esses correlatos (REETZ; JONGMAN, 2009). No PB, embora Mattoso Câmara Jr. (1972) apontasse o F0 como o principal correlato acústico do acento, estudos mais atuais apontam a duração como o parâmetro acústico mais importante para a definição do acento lexical (MAJOR, 1992; MASSINI, 1992; BARBOSA, 2000; FERREIRA, 2008). No caso do inglês, uma sílaba acentuada apresenta tipicamente frequência fundamental mais alta, maior duração e maior intensidade em comparação com sílabas átonas, sendo o pitch o correlato mais importante (FRY, 1958; BOLINGER, 1986).

Além dos parâmetros acústicos de acento, as línguas também diferem com relação ao ritmo. Há línguas que apresentam ritmo acentual, apresentando intervalos regulares entre os acentos independentemente do número de sílabas entre eles (ex: inglês, russo e árabe), e outras que possuem ritmo silábico, nas quais os intervalos entre acentos aumentam de acordo com o número de sílabas entre eles (ex: espanhol, francês e italiano) (MASSINI, 1992).

Diferentemente do inglês, cujo ritmo é normalmente caracterizado como acentual, o PB gera discussões com relação a esse aspecto. Segundo Abaurre-Gnerre (1981), o ritmo do $\mathrm{PB}$ não pode ser considerado absolutamente silábico ou acentual devido à variação dialetal, sendo as variantes da Bahia e do Rio Grande do Sul mais silábicas e as variantes do Rio de Janeiro e do Espírito Santo, mais acentuais. Segundo a autora, mesmo dentro da mesma região uma língua pode apresentar padrões acentuais diferentes, a depender do estilo de fala: enquanto a fala formal e lenta caracteriza um ritmo mais silábico, a fala informal e rápida caracteriza um ritmo mais acentual. Massini (1992) também aponta que o PB apresenta características tanto do ritmo acentual quanto do silábico. De acordo com a autora, enquanto o falar gaúcho apresenta um ritmo mais silábico, o falar paulistano é mais acentual, já que as sílabas apresentam durações muito diferentes entre si. Barbosa (2000) defende que a dicotomia ritmo silábico/acentual deve ser vista apenas como um rótulo indicativo de tendências nas línguas estudadas.

No entanto, um fenômeno rítmico comum a todas as línguas é a preferência por uma alternância entre sílabas fortes (acentuadas) e sílabas fracas (com acento mais fraco ou sem acento), conhecido como Princípio de Alternância Rítmica (Principle of Rythmic Alternation - SELKIRK, 1984) ou Eurritmia (NESPOR; VOGEL, 1986). Por conta dessa tendência, evita-se duas sílabas acentuadas em sequência, o que causa um choque acentual. Segundo Liberman e Prince (1977), o choque acentual não se caracteriza por qualquer sequência fonética de acentos fortes, pois apenas acentos 
adjacentes em uma mesma linha da grade métrica são considerados como acentos em colisão sujeitos a fenômenos de reajuste rítmico.

Os estudos sobre ritmo de Selkirk (1984), sobre o inglês, e de Abousalh (1997), entre outros, sobre o PB, apontam que a estratégia de retração de acento é utilizada por falantes dessas línguas para a resolução de choques acentuais. A retração, que ocorre dentro do domínio da frase fonológica nessas línguas, faz com que o acento da primeira palavra que constitui o choque seja deslocado para a esquerda, de modo a privilegiar a alternância entre sílabas fortes e fracas.

\section{Retração de acento em inglês}

$\mathrm{O}$ acento do inglês pode ocorrer numa janela de quatro sílabas (e.g. kangaROO 'canguru', toMAto 'tomate', ARticle 'artigo' e CAtegory 'categoria'). Segundo Selkirk (1984), a alternância entre sílabas fracas e fortes define uma organização rítmica ideal para o inglês, e a retração de acento é reconhecida como um recurso para evitar o choque acentual - cf. (1) (exemplos de HAYES, 1984, p. 33):3,4
(1) a. fourTEEN
$\rightarrow$ FOURteen WOmen
'quatorze mulheres'
b. MissiSSIppi
$\rightarrow$ MIssissippi LEgislature
'legislação do Mississipi'

Hayes (1984) argumenta que choques acentuais se reorganizam de maneira gradativa, sendo que acentos adjacentes são rigorosamente evitados e acentos próximos, mas não-adjacentes tendem a ocorrer com menos rigor por obedecer uma sequência acentual forte-fraco.

Há casos, entretanto, em que o choque acentual é mantido no inglês. O reajuste do acento não ocorre, por exemplo, quando as duas palavras estão separadas pelo limite entre duas frases fonológicas (HAYES, 1989), isto é, a retração de acento ocorre apenas dentro de uma mesma frase fonológica (ex: ([I] $\phi$ [saw] $\phi$ [THIRteen MEN] $\phi$ [in the park] $\phi$ 'Eu vi treze homens no parque'). ${ }^{5} \mathrm{O}$ choque também é mantido quando a vogal da sílaba que receberia o acento em caso de retração é um schwa, como na sequência maroon coat (/məRU:N KOðT/ 'casaco castanho'), em que o acento na sílaba -roon não pode recair sobre $m a$ - porque a vogal reduzida não pode receber o acento (LEVEY, 1999).

No entanto, Cooper e Eady (1986) mediram a duração e o pitch de sílabas em sequência de choque acentual do inglês e não observaram nenhum indício de mudança desses correlatos neste contexto. Segundo os autores, é difícil identificar os correlatos acústicos que influenciam a ocorrência do choque acentual porque os valores absolutos

\footnotetext{
Letras maiúsculas são utilizadas para marcar a sílaba portadora de acento de palavra.

Veja também Levey e Lawrence (2002) para outras estratégias de resolução.

Para as regras de construção de frases fonológicas, ver Nespor e Vogel (1986).
} 
de uma sílaba isolada nem sempre podem indicar alguma tendência de mudança de ritmo na sentença como um todo. Através da combinação entre uma análise perceptual e uma análise acústica, Levey (1999) também buscou investigar as características fonéticas do choque acentual por falantes de inglês. A verificação perceptual mostrou que a resolução do choque acentual ocorreu em $27 \%$ dos casos, inclusive em sequências onde não havia o choque. A verificação acústica, por sua vez, apontou que a frequência fundamental foi a única pista que poderia influenciar percepção da retração de acento, mas não foram encontradas evidências suficientes para afirmar que o F0 é, de fato, o correlato acústico responsável pela retração.

Autores como Grabe e Warren (1995) e Kimball e Cole (2014) sugerem que a retração de acento é, na verdade, um fenômeno de natureza perceptual, e não acústica. Grabe e Warren (1995) desenvolveram um experimento de percepção em que os participantes deveriam apontar a sílaba acentuada em uma série de palavras. Quando solicitados para identificar o acento em sequências de choque acentual como thirTEEN $M E N$ 'treze homens', os participantes perceberam uma retração acentual, ou seja, THIRteen MEN. Quando a mesma palavra THIRteen foi apresentada isoladamente, entretanto, os participantes identificaram o acento como thirTEEN.

\section{Retração de acento no português brasileiro}

No PB, o acento primário pode ocorrer nas três últimas sílabas. De acordo com Abousalh (1997) e Gayer e Collischonn (2007), várias são as estratégias de resolução do choque acentual na língua: deslocamento de um dos acentos, desacentuação de uma das proeminências, inserção de uma pausa e retração de acento.

Gayer e Collischonn (2007) analisaram as estratégias utilizadas por falantes de Porto Alegre e São Borja (RS) em situações de choque acentual e verificaram a seguinte distribuição de estratégias: $7 \%$ de retração; $20 \%$ de inserção de pausa; $61 \%$ de desacentuação de uma das proeminências; $4 \%$ de posposição do segundo acento e $8 \%$ de permanência do choque acentual. Apesar de as ocorrências de retração de acento não apresentarem uma quantidade expressiva, a pesquisa confirmou a ocorrência dessa estratégia em tais variantes do PB.

Segundo Abousalh (1997), se o condicionamento para a retração de acento fosse apenas rítmico, seria esperado que os choques acentuais fossem sempre desfeitos, pois trata-se de uma violação da regra de alternância rítmica. Seu estudo revela que, para que um choque acentual seja desfeito, ele precisa estar dentro de uma mesma frase fonológica (SELKIRK, 1984; NESPOR; VOGEL, 1986) e choques de acento em fronteiras de frase fonológica não são desfeitos. O exemplo (2) (exemplo de Tenani (2017, p.117) ilustra a questão. Em (2a), Jornal Hoje é o nome de um telejornal brasileiro, enquanto que em (2b), hoje refere-se ao dia em que um determinado jornal foi visto. Segundo as regras de mapeamento prosódico, Jornal Hoje (2a) constitui uma única frase fonológica, enquanto que jornal hoje (2b) são mapeados como duas frases fonológicas diferentes. 
O diferente mapeamento prosódico em domínios explica porque a retração acentual é aceita apenas em (2a), pois as duas palavras que constituem o choque se encontram na mesma frase fonológica. Em (2b) a regra é bloqueada porque cada palavra pertence a uma frase fonológica distinta, o que não permite o movimento do acento.

(2) a. [Você] $\phi[\mathrm{viu}] \phi[$ [o jorNAL HOje? $] \phi$

b. [Você] $\phi[\mathrm{viu}] \phi[\mathrm{o}$ jorNAL] $] \phi[H O j e ?] \phi$

Por sua vez, Sândalo e Truckenbrodt (2002) defendem que o choque acentual estar dentro de uma mesma frase fonológica também não é suficiente para justificar o reajuste do acento. Segundo os autores, a retração ocorre quando as frases fonológicas têm o mesmo tamanho prosódico, ou seja, quando possuem o mesmo número de palavras fonológicas. Assim, a retração é permitida em (3a), mas não em (3b) (exemplos dos autores):

(3) a. [caFÉ QUENte] $\phi$ [queima a boca $] \phi \rightarrow$ [CAfé QUENte] $\phi$ [queima a boca] $\phi$ b. [caFÉ QUENte] $\phi$ [queima] $\phi \quad \rightarrow$ \#[CAfé QUENte] $\phi[$ queima] $\phi$

Santos (2003) mostra que informações sintáticas também são relevantes para a aplicação ou bloqueio do processo, já que categorias sintáticas vazias como pro, se estiverem entre as duas sílabas acentuadas, impedem a retração do acento.

Para verificar o caráter fonético da retração de acento no PB, Barbosa (2002) e Madureira (2002) investigaram se as estratégias de desfazimento do choque acentual demonstradas fonologicamente na língua também ocorriam numa perspectiva fonéticoacústica. Barbosa (2002) analisou o acento a partir do parâmetro da duração e mostra que, em vez de retração de acento, houve um aumento na duração da sílaba oxítona da primeira palavra do choque, ou seja, um favorecimento para a ocorrência de choque acentual. Madureira (2002) analisou, além da duração, a frequência fundamental (F0), e também chega à conclusão de que a retração acentual não foi a estratégia escolhida pelos informantes.

Todos os estudos anteriores analisaram contextos de encontros acentuais primários. Observe-se que, enquanto a retração em (4a) é possível porque há um choque entre dois acentos primários, a retração causaria estranhamento em sequências como (4b), em que o choque de acento se dá entre um acento primário e um acento secundário.

(4) a. caFÉ QUENte $\rightarrow$ CAfé QUENte

b. caFÉ requenTAdo $\rightarrow$ ? CAfé requenTAdo

\section{Retração de acento do inglês por falantes brasileiros}

O trabalho de Silva Jr. (2013) é o único, até onde sabemos, que comparou a produção de sequências de choque acentual nas duas línguas em questão. $\mathrm{O}$ autor investigou se o 
ritmo do PB influencia a produção do inglês como L2 através da análise de sequências de choque acentual inseridas no domínio da frase fonológica no inglês e no PB por falantes de português como L1. Seu objetivo foi verificar se os informantes brasileiros prefeririam o movimento de batida ou a inserção de batida silenciosa para resolver choques de acento.

Foram analisadas produções de três brasileiros falantes de inglês como L2 e dois norte-americanos falantes de português como L2. Os informantes brasileiros foram divididos em três níveis de proficiência: $C 1$ (advanced), B2 (high intermediate) e B1 (low intermediate). $\mathrm{O}$ corpus foi composto de 20 sentenças, nove assertivas e uma interrogativa em inglês e oito assertivas e duas exclamativas em português, todas contendo alguma sequência de palavras com choque acentual em inglês (ex: thirTEEN $B A L L S$ 'treze bolas') ou em português (ex: muLHER Ótima). Através da verificação dos correlatos acústicos empregados, de modo individual os resultados mostraram que, em vez de retração acentual, a inserção de um curto pulso rítmico silencioso - ou, de acordo com Selkirk (1984), uma "batida silenciosa" - foi a estratégia mais empregada pelos falantes brasileiros para a resolução do choque em ambas as línguas. Os falantes norte-americanos, por outro lado, preferiram a estratégia de movimento de batida, ou seja, a retração de acento.

Em seguida, um norte-americano falante do PB como L2 e um brasileiro falante do inglês como L2, ambos não-informantes da tese, ouviram cada uma das sequências produzidas pelos primeiros informantes e indicaram a sílaba acentuada nas sequências. Apesar de não ter apresentado uma comparação estatística entre os resultados da percepção dos dois ouvintes e os resultados obtidos através de análise acústica, o autor conclui que há, definitivamente, diferenças entre a percepção da retração acentual e a retração acentual detectada no sinal acústico. Em outras palavras, os ouvintes tenderam a perceber os intervalos acentuais como sendo mais regulares do que eles realmente são quando analisados acusticamente.

\section{Metodologia $^{6}$}

Esta pesquisa contou com 30 informantes brasileiros aprendizes de inglês como L2 e sete falantes nativos de inglês. Os brasileiros não moraram em país anglófono por mais de um mês, eram filhos de pais brasileiros monolíngues e não falavam nenhuma outra língua estrangeira além do inglês. Os nativos viveram a maior parte da vida em seus países de origem. A amostra é do tipo aleatória estratificada (LEVIN; FOX, 2004), selecionando os aprendizes pelo nível de proficiência em L2. O nivelamento foi para 3 grupos (básico, intermediário e avançado), com base no Common European Framework of Reference for Languages (COUNCIL OF EUROPE, 2001). Os informantes foram

Esta pesquisa foi aprovada pelo Comitê de Ética do Instituto de Psicologia da Universidade de São Paulo - CAAE 46139815.1.0000.5561. 
nivelados em duas etapas: um teste on-line de questões de múltipla escolha e um teste de proficiência oral (ambos oferecidos pelo site de Cambridge). O teste online serviu de base para o nível do teste oral a ser aplicado. O nivelamento ocorreu de acordo com o desempenho no teste oral.

Foi desenvolvido um experimento de produção contendo 21 palavras oxítonas em três contextos: isoladas (ex: thirTEEN 'treze'), inseridas em frases com sequência de choque acentual (ex: thirTEEN MEN 'treze homens') e inseridas em frases sem sequência de choque acentual (ex: thirTEEN poTAtoes 'treze batatas') - cf. Quadro 1 -a fim de observar como os falantes nativos e não nativos aplicam o acento nas mesmas palavras em cada um desses contextos. ${ }^{7}$

Quadro 1 - Palavras e Sequências de Palavras do Experimento

\begin{tabular}{|c|c|c|}
\hline Palavra Isolada & $\begin{array}{l}\text { Sequências de } \\
\text { choque acentual }\end{array}$ & Sequências sem choque acentual \\
\hline 1. thirTEEN & 1. thirTEEN PENcils & 1. thirTEEN poTAtoes \\
\hline 2. fourTEEN & 2. fourTEEN WOmen & 2. fourTEEN baNAnas \\
\hline 3. fifTEEN & 3. fifTEEN GIRLS & 3. fifTEEN toMAtoes \\
\hline 4. sixTEEN & 4. SixTEEN CHAIRS & 4. sixTEEN imiTAtions \\
\hline 5. sevenTEEN & 5. sevenTEEN YEARS & 5. sevenTEEN paPAYas \\
\hline 6. eighTEEN & 6. eighTEEN CHILdren & 6. eighTEEN adVENtures \\
\hline 7. nineTEEN & 7. nineTEEN BOYS & 7. nineTEEN eXAMples \\
\hline 8. unKIND & 8. unKIND COmment & 8. unKIND reVENge \\
\hline 9. kangaROO & 9. kangaROO KIM & 9. kangaROO MeLIssa \\
\hline 10. TenneSSEE & 10. TenneSSEE PEOPLE & 10. TenneSSEE volCAno \\
\hline 11. groTESQUE & 11. groTESQUE PICtures & 11. groTESQUE deCEPtion \\
\hline 12. roBUST & 12. roBUST BAbies & 12. roBUST umBRElla \\
\hline 13. bamBOO & 13. bamBOO BRAcelets & 13. bamBOO maTErials \\
\hline 14. poLICE & 14. poLICE OFFICER & 14. poLICE conVENtion \\
\hline 15. disCRETE & 15. disCRETE AREAS & 15. disCREET beGInning \\
\hline 16. comPLETE & 16. comPLETE PAper & 16. comPLETE comPUters \\
\hline 17. Bel-AIR & 17. Bel-AIR BOY & 17. Bel-AIR ceLEbrity \\
\hline 18. U2 & 18. U2 SONG & 18. U2 celeBRAtion \\
\hline 19. $\operatorname{reTAKE~(v.)~}$ & 19. reTAKE COURSE & 19. reTAKE examiNATION \\
\hline 20. exPRESS & 20. exPRESS TRAIN & 20. exPRESS transforMAtions \\
\hline 21. disLIKE & 21. disLIKE CHOcolate & 21. disLIKE perFECtionism \\
\hline & 22. disLIKE POWer & 22. disLIKE conFUsion \\
\hline & 23. disLIKE PROblems & 23. disLIKE poliTIcians \\
\hline
\end{tabular}

Fonte: Elaboração própria.

As frases e palavras foram apresentadas em ordem aleatória, misturadas a 152 sintagmas e sentenças distratoras. 
De modo a evitar qualquer influência do contexto sintático ou prosódico sobre a retração de acento, todas as sequências de palavras foram inseridas em frases fonológicas do mesmo tamanho e no mesmo tipo de frase veículo, conforme os exemplos em (5):

(5) a) [I saw] [grotESQUE PICtures] [in the park].

Eu vi grotescas fotos em o parque

'Eu vi fotos grotescas no parque.'

b) [I have] [thirTEEN poTAtoes] [at home].

Eu tenho treze batatas em casa

'Eu tenho treze batatas em casa.'

A verificação perceptual da posição do acento seguiu os procedimentos aplicados por Levey (1999) e Stander (2007): cada palavra do corpus teve o acento sinalizado por duas especialistas em aspectos fonético-fonológicos do inglês. Casos de discordância eram discutidos até que se chegasse a um consenso a respeito das sílabas acentuadas.

Para este estudo, a variável dependente é a ocorrência de retração de acento e os fatores são: houve retração (ex: THIRteen MEN) e não houve retração (ex: thirTEEN $M E N)$. O Quadro 2 apresenta os fatores das variáveis controlados.

Quadro 2 - Variáveis Controladas - Retração de Acento

\begin{tabular}{|c|c|c|}
\hline $\begin{array}{c}\text { VARIÁVEL } \\
\text { DEPENDENTE }\end{array}$ & $\begin{array}{c}\text { Ocorrência da } \\
\text { Retração de Acento }\end{array}$ & \begin{tabular}{|l} 
Houve retração \\
Não houve retração
\end{tabular} \\
\hline \multirow{7}{*}{$\begin{array}{c}\text { VARIÁVEIS } \\
\text { INDEPENDENTES }\end{array}$} & Contexto & $\begin{array}{l}\text { Palavra Isolada } \\
\text { Frase Com Choque } \\
\text { Frase Sem Choque } \\
\end{array}$ \\
\hline & Palavra Alvo & Cada uma das 21 palavras analisadas \\
\hline & $\begin{array}{c}\text { Padrão Acentual } \\
\text { Empregado }\end{array}$ & \begin{tabular}{|l} 
Oxítono \\
Paroxítono \\
Proparoxítono \\
\end{tabular} \\
\hline & $\begin{array}{l}\text { Segmento na } \\
\text { Sílaba Final }\end{array}$ & \begin{tabular}{|l} 
Vogal Longa \\
Vogal Longa + nasal \\
Vogal Longa + obstruinte \\
\end{tabular} \\
\hline & Pausa & $\begin{array}{l}\text { Com Pausa } \\
\text { Sem Pausa }\end{array}$ \\
\hline & Nível de Proficiência & \begin{tabular}{|l} 
Básico \\
Intermediário \\
Avançado \\
Falante Nativo \\
\end{tabular} \\
\hline & Informante & $1,2 \ldots 37$ \\
\hline
\end{tabular}

Fonte: Elaboração própria. 
Para que a ocorrência da retração acentual fosse contabilizada, a variável dependente foi relacionada com a variável contexto, que indica se a palavra foi produzida em uma frase com choque acentual, em uma frase sem choque acentual ou isolada. Uma palavra como fifTEEN 'quinze', por exemplo, poderia ser produzida isoladamente como FIFteen, por influência da regra de acento de $\mathrm{PB}$, que privilegia produções paroxítonas (CINTRA, 1997). Nesse caso, a atribuição do acento na sílaba fif- em uma sequência como FIFteen MEN ‘quinze homens' pelo mesmo informante não indicaria uma ocorrência de retração de acento, pois não houve mudança no padrão acentual empregado no contexto de palavra isolada e no caso de choque acentual. Sendo assim, a ocorrência de retração só foi considerada quando o falante produziu o padrão oxítono na palavra isolada (ex: fifTEEN) e o padrão paroxítono ou proparoxítono nas frases com choque (ex: FIFteen MEN) ou sem choque (ex: FIFteen poTAtoes 'quinze batatas'). A variável Palavra Alvo foi incluída para verificar o padrão acentual empregado pelos informantes em cada uma das 21 palavras analisadas. É importante salientar que, apesar de a retração não ser possível em palavras como police 'polícia' e complete 'completo' na fala de nativos por conterem a vogal reduzida schwa [ə] na sílaba que receberia o acento em caso de retração ([kəm'pli:t], [pə'li:s]), esses dados permitiam observar o que os aprendizes, sobretudo no nível básico, tendem a produzir vogais plenas nesses contextos, o que possibilita a análise da retração nesses casos.

Com a variável Padrão Acentual Empregado verificou-se o padrão acentual efetivamente produzido pelos falantes. Os fatores desta variável são Oxítono, Paroxitono e Proparoxitono, que são os padrões acentuais mais comuns no PB e no inglês.

A variável Pausa foi incluída para controlar os casos em que o informante fez uma pausa entre as duas palavras nas sequências com choque e sem choque acentual mesmo tendo sido instruídos a realizar a leitura das frases sem interrupções e da forma mais natural possível. Entretanto, houve casos em que os informantes não conseguiram realizar a leitura das frases sem a inserção de pausa, mesmo quando solicitados para repetir a leitura sem interrupções, principalmente no nível básico. Por isso, controlamos essas ocorrências de pausa através desta variável, cujos fatores são Com Pausa e Sem Pausa.

Incluiu-se a variável Segmento na Sílaba Final para verificar a influência do padrão silábico da sílaba final da primeira palavra do choque sobre a aplicação da regra. Os fatores analisados foram: vogal longa (ex: bamBOO 'bambu'), nasal (ex: thirTEEN 'treze') e obstruinte (ex: japaNESE 'japonês') ${ }^{8}$. Além dessas variáveis linguísticas, as variáveis sociais Nivel de Proficiência (básico, intermediário e avançado) e Informante também foram controladas na análise.

A verificação estatística dos dados classificados através de julgamento perceptual foi realizada através do programa GoldVarb-X. A aplicação da regra de retração de acento tem caráter binário (aplicou/não aplicou a retração), portanto, é condizente com o tipo de teste estatístico oferecido pelo programa mencionado.

Nessas palavras há a possibilidade de inserção de epêntese na sílaba final, principalmente no nível básico, o que bloquearia o choque acentual (ex: com.PLE.te PApers 'papéis completos'). 


\section{Resultados}

Foram obtidos 2.645 dados e só foram consideradas ocorrências de retração os casos em que o informante apresentou o padrão oxítono na palavra isolada (ex: fifTEEN, sevenTEEN) e o padrão paroxítono (ex: FIFteen MEN 'quinze homens') ou proparoxítono (ex: SEventeen MEN 'dezessete homens') na mesma palavra em frases com ou sem sequência de choque acentual. Ressaltamos que os resultados referentes aos falantes nativos e não nativos incluem somente as ocorrências de palavras inseridas em frases (com choque e sem choque), já que as palavras produzidas isoladamente foram utilizadas apenas como um parâmetro para controlar os casos em que houve retração.

\section{Falantes nativos}

Das 21 palavras oxítonas do experimento, três foram classificadas como paroxítonas quando lidas isoladamente na fala de nativos: discrete 'discreto', nineteen 'dezenove' e thirteen 'treze'. Nesses casos, ainda que essas palavras também tenham sido produzidas como paroxítonas em frases com choque e sem choque, a ocorrência de retração de acento não foi contabilizada, já que não houve mudança na posição do acento nos diferentes contextos analisados.

A taxa de aplicação da retração de acento pelos sete falantes nativos foi de 50,6\% (163/322), tanto em frases com sequência de choque quanto em frases sem sequência de choque acentual. Na primeira rodada estatística, as variáveis Palavra e Acento Empregado apresentaram knockout. Por isso, realizou-se uma nova rodada, excluindo-se essas duas variáveis da análise multidimensional. Dentre as variáveis restantes, somente Segmento Final foi selecionada como estatisticamente significativa.

A variável Contexto não foi estatisticamente significativa para a aplicação da retração de acento pelos falantes nativos, mas trazemos os resultados descritivos para ver o que ocorre. Como se observa na Tabela 1, 49,7\% dos casos de retração ocorreram em frases com uma sequência de choque acentual e 51,6\% em frases sem choque acentual, uma taxa de aplicação da regra nos dois grupos bastante próxima.

Tabela 1 - Retração de Acento por Contexto - Nativos

\begin{tabular}{ccccc}
\hline \multirow{2}{*}{ Contexto } & \multicolumn{2}{c}{ Retração } & \multicolumn{2}{c}{ Sem retração } \\
\cline { 2 - 5 } & $\mathbf{N}$ & $\mathbf{\%}$ & $\mathbf{N}$ & $\mathbf{\%}$ \\
\hline Frase Com Choque & 80 & $49,7 \%$ & 81 & $50,3 \%$ \\
Frase Sem Choque & 83 & $51,6 \%$ & 78 & $48,4 \%$ \\
\hline
\end{tabular}

Fonte: Elaboração própria. 
A Tabela 2 apresenta os resultados referentes à variável Segmento Final, a única que se mostrou estatisticamente relevante para a aplicação da retração de acento pelos falantes nativos. Palavras terminadas em nasal e vogal longa favoreceram a aplicação da regra, enquanto que palavras terminadas em uma consoante obstruinte desfavoreceram a aplicação da regra.

Tabela 2 - Retração de Acento e Segmento Final - Nativos

\begin{tabular}{|c|c|c|c|c|c|}
\hline \multirow{2}{*}{ Segmento Final } & \multicolumn{2}{|c|}{ Retração } & \multicolumn{2}{|c|}{ Sem retração } & \multirow{2}{*}{$\begin{array}{c}\text { PESO } \\
\text { RELATIVO }\end{array}$} \\
\hline & $\mathbf{N}$ & $\%$ & $\mathbf{N}$ & $\%$ & \\
\hline Nasal & 78 & $79,6 \%$ & 20 & $20,4 \%$ & 0,80 \\
\hline Vogal Longa & 42 & $75 \%$ & 14 & $25 \%$ & 0,75 \\
\hline Obstruinte & 43 & $25,6 \%$ & 125 & $74,4 \%$ & 0,23 \\
\hline
\end{tabular}

Fonte: Elaboração própria.

A Tabela 3 apresenta a taxa de aplicação da regra por Palavra Alvo, variável que não pôde ser incluída na análise multidimensional por causa da ocorrência de knockouts.

Tabela 3 - Retração de Acento por Palavra Alvo - Nativos

\begin{tabular}{ccccc|ccccc}
\hline \multirow{2}{*}{$\begin{array}{c}\text { Palavra } \\
\text { Alvo }\end{array}$} & \multicolumn{2}{c}{ Retração } & Sem retração & \multirow{2}{*}{ Palavra } & \multicolumn{2}{c}{ Retração } & \multicolumn{2}{c}{ Sem Retração } \\
\cline { 2 - 3 } & $\mathbf{N}$ & $\mathbf{\%}$ & $\mathbf{N}$ & $\mathbf{\%}$ & Alvo & $\mathbf{N}$ & $\mathbf{\%}$ & $\mathbf{N}$ & $\mathbf{\%}$ \\
\hline Eighteen & 14 & $100 \%$ & 0 & 0 & Fifteen & 7 & $50 \%$ & 7 & $50 \%$ \\
Seventeen & 14 & $100 \%$ & 0 & 0 & $U 2$ & 6 & $42,9 \%$ & 8 & $57,1 \%$ \\
sixteen & 12 & $85,7 \%$ & 2 & $14,3 \%$ & dislike & 16 & $41 \%$ & 23 & $59 \%$ \\
Tennessee & 12 & $85,7 \%$ & 2 & $14,3 \%$ & Bel-Air & 5 & $35,7 \%$ & 9 & $64,3 \%$ \\
bamboo & 12 & $85,7 \%$ & 2 & $14,3 \%$ & robust & 2 & $14,3 \%$ & 12 & $85,7 \%$ \\
kangaroo & 12 & $85,7 \%$ & 2 & $14,3 \%$ & grotesque & 0 & 0 & 14 & $100 \%$ \\
fourteen & 11 & $78,6 \%$ & 3 & $21,4 \%$ & complete & 0 & 0 & 14 & $100 \%$ \\
retake & 11 & $78,6 \%$ & 3 & $21,4 \%$ & discrete & 0 & 0 & 14 & $100 \%$ \\
thirteen & 11 & $78,6 \%$ & 3 & $21,4 \%$ & police & 0 & 0 & 14 & $100 \%$ \\
nineteen & 9 & $64,3 \%$ & 5 & $35,7 \%$ & express & 0 & 0 & 14 & $100 \%$ \\
unkind & 9 & $64,3 \%$ & 5 & $35,7 \%$ & & & & & \\
\hline
\end{tabular}

Fonte: Elaboração das autoras.

Pode-se observar que as palavras eighteen 'dezoito' e seventeen 'dezessete' foram as únicas que apresentaram $100 \%$ de aplicação da regra. Isso significa que todos os falantes nativos aplicaram o padrão oxítono quando produziram essas palavras individualmente e, em frases (com e sem choque) aplicaram o padrão paroxítono. No outro extremo, 
as palavras grotesque 'grotesco', complete 'completo', discrete 'discreto', express ‘expresso' e police 'polícia' não apresentaram nenhum caso de retração.

Percebe-se que o fato de palavras terminadas em consoante nasal terem favorecido a retração (cf. Tabela 2) está relacionado ao fato de as palavras eighteen, seventeen e sixteen 'dezesseis', todas terminadas em consoante nasal, terem apresentado as maiores taxas de aplicação da regra (cf. Tabela 3). Já o fato de palavras terminadas em vogal longa também terem favorecido a aplicação da regra pode ser explicado pelo fato de as palavras Tennessee “Tenessi', bamboo 'bambu' e kangaroo 'canguru', terminadas em vogal longa, terem apresentado altas taxas de aplicação da retração. Palavras terminadas em obstruinte, por fim, desfavoreceram a aplicação da regra porque este é o padrão silábico encontrado nas palavras grotesque, complete, discrete, police e express, que não apresentaram nenhuma ocorrência de retração de acento.

A Tabela 4 apresenta os resultados referentes à variável Padrão Acentual Empregado, que também teve de ser excluída nas rodadas estatísticas, mas nos permite observar qual foi o padrão acentual aplicado pelos falantes nativos nos casos em que houve retração e nos casos em que não houve. Observa-se que em 95,4\% dos casos, a retração ocorreu em palavras oxítonas que se tornaram paroxitonas quando inseridas em frases (ex: fiftEEN $\rightarrow$ FIFteen). Em 95\% a retração ocorreu em palavras oxítonas que se tornaram proparoxitonas em contexto de choque (ex: kangaROO $\rightarrow$ KANgaroo). Os 6 casos em que os informantes aplicaram o padrão paroxítono e os 2 casos em que empregaram o padrão proparoxítono nas frases em que a retração não foi contabilizada ocorreram porque os falantes empregaram esse mesmo padrão acentual nas palavras produzidas individualmente, o que não caracteriza a aplicação da regra. Por fim, as palavras em que os informantes aplicaram o padrão oxítono apresentam $0 \%$ de aplicação da regra porque isso significa que a palavra era oxítona e continuou oxítona em contexto de frases com choque, o que não caracteriza a retração.

Tabela 4 - Retração de Acento e Padrão Acentual Empregado - Nativos

\begin{tabular}{ccccc}
\hline \multirow{2}{*}{$\begin{array}{c}\text { Padrão Acentual } \\
\text { Empregado }\end{array}$} & \multicolumn{2}{c}{ Retração } & \multicolumn{2}{c}{ Sem retração } \\
\cline { 2 - 5 } & $\mathbf{N}$ & $\mathbf{\%}$ & $\mathbf{N}$ & $\mathbf{\%}$ \\
\hline Paroxitona & 125 & $95,4 \%$ & 6 & $4,6 \%$ \\
Proparoxitona & 38 & $95 \%$ & 2 & $5 \%$ \\
Oxítona & 0 & 0 & 151 & $100 \%$ \\
\hline
\end{tabular}

Fonte: Elaboração das autoras.

\section{Falantes de inglês como L2}

A Tabela 5 apresenta o padrão acentual em cada palavra produzida isoladamente por falantes do PB. Percebe-se que em 11 palavras a porcentagem de aplicação do 
padrão oxítono, o padrão esperado neste contexto, foi bem mais alta do que os outros dois padrões. Nas outras 10 palavras, entretanto, a aplicação do padrão paroxítono ou proparoxítono foi quase a mesma do padrão oxítono. Nesses casos, a ocorrência do padrão paroxítono ou proparoxítono nas palavras inseridas em frases com ou sem choque não foi classificada como retração de acento, já que não houve modificação no padrão acentual empregado nos diferentes contextos.

Tabela 5 - Padrão Acentual Aplicado na Palavra Isolada - Inglês como L2

\begin{tabular}{|c|c|c|c|c|c|c|}
\hline \multirow{3}{*}{$\begin{array}{c}\text { Palavra } \\
\text { Alvo }\end{array}$} & \multicolumn{6}{|c|}{ ACENTO APLICADO NA PALAVRA ISOLADA } \\
\hline & \multicolumn{2}{|c|}{ Oxítono } & \multicolumn{2}{|c|}{ Paroxítono } & \multicolumn{2}{|c|}{ Proparoxítono } \\
\hline & N/Total & $\%$ & $\mathrm{~N} /$ Total & $\%$ & $\mathrm{~N} /$ Total & $\%$ \\
\hline Bamboo & $24 / 30$ & 80 & $6 / 30$ & 20 & & \\
\hline Bel-Air & $26 / 30$ & 86,6 & $4 / 30$ & 13,4 & & \\
\hline Complete & $25 / 30$ & 83,3 & $5 / 30$ & 16,7 & & \\
\hline Discrete & $23 / 30$ & 76,6 & $7 / 30$ & 23,4 & & \\
\hline Dislike & $26 / 30$ & 86,6 & $4 / 30$ & 13,4 & & \\
\hline Eighteen & $16 / 30$ & 53,3 & $14 / 30$ & 46,6 & & \\
\hline Express & $28 / 30$ & 93,3 & $2 / 30$ & 7,7 & & \\
\hline Fifteen & $13 / 30$ & 43,3 & $17 / 30$ & 56,5 & & \\
\hline Fourteen & $18 / 30$ & 60 & $12 / 30$ & 40 & & \\
\hline Grotesque & $23 / 30$ & 76,6 & $7 / 30$ & 23,4 & & \\
\hline Kangaroo & $15 / 30$ & 50 & $1 / 30$ & 3,3 & $14 / 30$ & 46,6 \\
\hline Nineteen & $16 / 30$ & 53,3 & $14 / 30$ & 46,7 & & \\
\hline Police & $15 / 30$ & 50 & $15 / 30$ & 50 & & \\
\hline Retake & $29 / 30$ & 96,7 & $1 / 30$ & 3,3 & & \\
\hline robust & $18 / 30$ & 60 & $12 / 30$ & 40 & & \\
\hline seventeen & $17 / 30$ & 56,6 & $0 / 30$ & 0 & $13 / 30$ & 43,4 \\
\hline sixteen & $18 / 30$ & 60 & $12 / 30$ & 40 & & \\
\hline Tennessee & $17 / 30$ & 56,6 & $3 / 30$ & 10 & $10 / 30$ & 33,4 \\
\hline thirteen & $14 / 30$ & 46,6 & $16 / 30$ & 53,3 & & \\
\hline$U 2$ & $26 / 30$ & 86,6 & $4 / 30$ & 13,4 & & \\
\hline Unkind & $23 / 30$ & 76,6 & $7 / 30$ & 23,4 & & \\
\hline
\end{tabular}

Fonte: Elaboração própria.

A retração de acento ocorreu em $28,7 \%$ dos casos (396/1378) e não foi aplicada em $71,3 \%$ dos dados (982/1378). A análise estatística selecionou, nesta ordem, as variáveis Nivel de Proficiência, e Palavra Alvo como estatisticamente relevantes. As 
variáveis Segmento Final, Contexto e Pausa não foram consideradas estatisticamente significativas.

A Tabela 6 apresenta os resultados referentes à variável Contexto, que, assim como nos dados dos falantes nativos, não foi estatisticamente significativa para a aplicação da retração de acento. Observa-se que houve mais casos de retração de acento em frases com choque acentual, mas a diferença entre esses dois tipos de frase não foi estatisticamente significativa.

Tabela 6 - Retração de Acento por Contexto - Inglês como L2

\begin{tabular}{ccccc}
\hline \multirow{2}{*}{ Contexto } & \multicolumn{2}{c}{ Retração } & \multicolumn{2}{c}{ Sem retração } \\
\cline { 2 - 5 } & $\mathbf{N}$ & $\mathbf{\%}$ & $\mathbf{N}$ & $\mathbf{\%}$ \\
\hline Frases com Choque & 206 & $29,9 \%$ & 483 & $70,1 \%$ \\
Frases sem Choque & 190 & $27,6 \%$ & 499 & $72,4 \%$ \\
\hline
\end{tabular}

Fonte: Elaboração própria.

Dentre as variáveis linguísticas testadas, apenas Palavra Alvo mostrou-se estatisticamente relevante na produção dos falantes de inglês como L2. Os resultados referentes a esta variável são apresentados na Tabela 7 a seguir, que inclui contextos de frase com choque e sem choque.

Tabela 7 - Retração de Acento por Palavra Alvo - Inglês como L2

\begin{tabular}{cccccc}
\hline \multirow{2}{*}{$\begin{array}{c}\text { Palavra } \\
\text { Alvo }\end{array}$} & \multicolumn{2}{c}{ Retração } & \multicolumn{2}{c}{ Sem retração } & $\begin{array}{c}\text { Peso } \\
\text { relativo }\end{array}$ \\
\cline { 2 - 5 } U2 & $\mathbf{N}$ & $\mathbf{\%}$ & $\mathbf{N}$ & $\mathbf{\%}$ & 0,75 \\
Seventeen & 30 & $50 \%$ & 30 & $50 \%$ & 0,74 \\
Sixteen & 29 & $48,3 \%$ & 31 & $51,7 \%$ & 0,72 \\
Nineteen & 26 & $43,3 \%$ & 34 & $56,7 \%$ & 0,68 \\
Fourteen & 24 & $40 \%$ & 36 & $60 \%$ & 0,64 \\
Unkind & 21 & $35 \%$ & 39 & $65 \%$ & 0,64 \\
Tennessee & 23 & $38,3 \%$ & 37 & $61,7 \%$ & 0,63 \\
thirteen & 23 & $38,3 \%$ & 37 & $61,7 \%$ & 0,63 \\
fifteen & 23 & $38,3 \%$ & 37 & $61,7 \%$ & 0,63 \\
kangaroo & 22 & $36,7 \%$ & 38 & $63,3 \%$ & 0,61 \\
eighteen & 22 & $36,7 \%$ & 38 & $63,3 \%$ & 0,61 \\
robust & 18 & $30 \%$ & 42 & $70 \%$ & 0,58 \\
bamboo & 20 & $33,3 \%$ & 40 & $66,7 \%$ & 0,57 \\
grotesque & 15 & $25,9 \%$ & 43 & $74,1 \%$ & 0,52 \\
express & 12 & $20 \%$ & 48 & $80 \%$ & 0,43
\end{tabular}




\begin{tabular}{cccccc}
\hline \multirow{2}{*}{$\begin{array}{c}\text { Palavra } \\
\text { Alvo }\end{array}$} & \multicolumn{2}{c}{ Retração } & \multicolumn{2}{c}{ Sem retração } & \multirow{2}{*}{$\begin{array}{c}\text { Peso } \\
\text { relativo }\end{array}$} \\
\cline { 2 - 4 } police & $\mathbf{N}$ & $\mathbf{\%}$ & $\mathbf{N}$ & $\mathbf{\%}$ & 0,43 \\
Bel-Air & 11 & $18,3 \%$ & 40 & $81,7 \%$ & 0,41 \\
discrete & 9 & $15 \%$ & 51 & $85 \%$ & 0,35 \\
retake & 8 & $13,3 \%$ & 52 & $86,7 \%$ & 0,31 \\
complete & 7 & $11,7 \%$ & 53 & $88,3 \%$ & 0,28 \\
dislike & 10 & $5,6 \%$ & 170 & $94,4 \%$ & 0,14 \\
\hline
\end{tabular}

Fonte: Elaboração própria.

Observa-se que, dentre todas as palavras testadas, a palavra composta $U 2$ foi a maior favorecedora da retração de acento entre os falantes não nativos, com taxa de aplicação de 51,7\%. Isso significa que, em 51,7\% dos casos, os falantes brasileiros aplicaram o padrão oxítono nesta palavra produzida isoladamente e, em frases com choque e sem choque aplicaram o padrão paroxítono.

A Tabela 8 apresenta os resultados referentes à variável Segmento Final, que não se mostrou estatisticamente significativa para a aplicação da retração de acento pelos aprendizes.

Tabela 8 - Retração de Acento e Segmento Final - Inglês como L2

\begin{tabular}{ccccc}
\hline \multirow{2}{*}{ Segmento Final } & \multicolumn{2}{c}{ Retração } & \multicolumn{2}{c}{ Sem retração } \\
\cline { 2 - 5 } & $\mathbf{N}$ & $\mathbf{\%}$ & $\mathbf{N}$ & $\mathbf{\%}$ \\
\hline Nasal & 177 & $42,1 \%$ & 243 & $57,9 \%$ \\
Vogal Longa & 96 & $40 \%$ & 144 & $60 \%$ \\
Obstruinte & 123 & $17,1 \%$ & 595 & $82,9 \%$ \\
\hline
\end{tabular}

Fonte: Elaboração própria.

O fato de vogais longas seguidas de nasal terem apresentado a maior taxa de aplicação da retração de acento está relacionado ao fato de que as palavras seventeen, sixteen, nineteen 'dezenove' e fourteen 'quatorze' apresentaram taxas de retração bastante altas (entre $40 \%$ e $50 \%$ ). Palavras terminadas em vogal longa também apresentaram uma taxa de aplicação alta porque a palavra que apresentou mais casos de retração foi $U 2$, cuja sílaba final apresenta uma vogal longa. Por fim, o fato de palavras terminadas em obstruinte terem apresentado a taxa de aplicação mais baixa está relacionado ao fato de palavras como discrete 'discreto', retake 'retomar', complete 'completo' e dislike 'não gostar' terem apresentado as taxas mais baixas de aplicação da regra.

A Tabela 9 apresenta o padrão acentual empregado pelos falantes brasileiros nos casos de retração de acento. Lembramos que esta variável tem caráter descritivo, ou seja, não foi incluída na análise multidimensional por causa da ocorrência de knockout. 
Tabela 9 - Retração de Acento e Padrão Acentual Empregado - Inglês como L2

\begin{tabular}{ccccc}
\hline \multirow{2}{*}{$\begin{array}{c}\text { Padrão Acentual } \\
\text { Empregado }\end{array}$} & \multicolumn{2}{c}{ Retração } & \multicolumn{2}{c}{ Sem retração } \\
\cline { 2 - 5 } & $\mathbf{N}$ & $\mathbf{\%}$ & $\mathbf{N}$ & $\mathbf{\%}$ \\
\hline Paroxitona & 320 & $54,4 \%$ & 268 & $45,5 \%$ \\
Proparoxítona & 76 & $54 \%$ & 65 & $46 \%$ \\
Oxítona & 0 & 0 & 649 & $100 \%$ \\
\hline
\end{tabular}

Fonte: Elaboração própria.

Observa-se que $54,4 \%$ dos casos em que os informantes aplicaram o padrão paroxítono foram ocorrências de retração de acento e que em 45,5\% dos casos os informantes aplicaram o padrão paroxítono tanto nas palavras produzidas individualmente quanto nas palavras inseridas em frases, o que não caracteriza a retração. Resultados semelhantes foram encontrados quando o padrão empregado foi o proparoxítono. As aplicações do padrão Oxitono indicam os casos em que a retração não foi aplicada.

A Tabela 10 apresenta o cruzamento entre as variáveis Padrão Acentual Empregado e Palavra Alvo e deve ser lida da seguinte forma: a palavra dislike, por exemplo, foi produzida como oxítona 171 vezes nas frases com choque e sem choque, o que significa que a retração não ocorreu em nenhum desses casos. Essa mesma palavra foi produzida com o padrão paroxítono em 9 casos, dos quais 8 foram ocorrências de retração de acento e 1 não foi (porque o padrão paroxítono também foi aplicado na palavra isolada). A palavra $U 2$, por sua vez, foi produzida como oxítona nas frases com choque e sem choque em 26 casos e como paroxítona em 36 casos, dos quais 29 foram ocorrências de retração de acento, e assim sucessivamente.

Tabela 10 - Acento empregado por palavra alvo - Inglês como L2

\begin{tabular}{ccccccc}
\hline \multirow{2}{*}{$\begin{array}{c}\text { Palavra } \\
\text { Alvo }\end{array}$} & \multicolumn{2}{c}{ ACENTO APLICADO EM CASOS DE RETRAÇÃO } \\
\cline { 2 - 7 } & Casos/Total & $\%$ & Casos/Total & $\%$ & Casos/Total & $\%$ \\
\cline { 2 - 7 } Dislike & $0 / 171$ & 0 & $8 / 9$ & $89 \%$ & 0 & 0 \\
U2 & $0 / 26$ & 0 & $29 / 36$ & $81 \%$ & 0 & 0 \\
Bamboo & $0 / 35$ & 0 & $20 / 25$ & $80 \%$ & 0 & 0 \\
Retake & $0 / 50$ & 0 & $8 / 10$ & $80 \%$ & 0 & 0 \\
express & $0 / 45$ & 0 & $12 / 15$ & $80 \%$ & 0 & 0 \\
unkind & $0 / 32$ & 0 & $21 / 28$ & $75 \%$ & 0 & 0 \\
Bel-Air & $0 / 45$ & 0 & $11 / 15$ & $73 \%$ & 0 & 0 \\
discrete & $0 / 46$ & 0 & $9 / 14$ & $64 \%$ & 0 & 0 \\
sixteen & $0 / 8$ & 0 & $29 / 52$ & $56 \%$ & 0 & 0
\end{tabular}




\begin{tabular}{ccccccc}
\hline \multirow{2}{*}{$\begin{array}{c}\text { Palavra } \\
\text { Alvo }\end{array}$} & \multicolumn{2}{c}{ ACENTO APLICADO EM CASOS DE RETRAÇÃO } \\
\cline { 2 - 7 } & Oxítono & \multicolumn{2}{c}{ Paroxítono } & \multicolumn{2}{c}{ Proparoxítono } \\
\cline { 2 - 7 } Casos/Total & $\%$ & Casos/Total & $\%$ & Casos/Total & $\%$ \\
\hline grotesque & $0 / 30$ & 0 & $15 / 28$ & $54 \%$ & 0 & 0 \\
complete & $0 / 47$ & 0 & $7 / 13$ & $54 \%$ & 0 & 0 \\
fourteen & $0 / 14$ & 0 & $24 / 46$ & $52 \%$ & 0 & 0 \\
nineteen & $0 / 6$ & 0 & $26 / 54$ & $48 \%$ & 0 & 0 \\
eighteen & $0 / 12$ & 0 & $22 / 48$ & $46 \%$ & 0 & 0 \\
robust & $0 / 19$ & 0 & $18 / 41$ & $44 \%$ & 0 & 0 \\
thirteen & $0 / 7$ & 0 & $23 / 53$ & $43 \%$ & 0 & 0 \\
fifteen & $0 / 4$ & 0 & $23 / 56$ & $41 \%$ & 0 & 0 \\
police & $0 / 25$ & 0 & $12 / 35$ & $34 \%$ & 0 & 0 \\
Tennessee & $0 / 13$ & 0 & $1 / 6$ & $17 \%$ & $22 / 41$ & $54 \%$ \\
seventeen & $0 / 4$ & 0 & $0 / 2$ & 0 & $30 / 54$ & $56 \%$ \\
kangaroo & $0 / 12$ & 0 & $0 / 2$ & 0 & $22 / 46$ & $48 \%$ \\
TOTAL & $\mathbf{0 / 6 5 1}$ & $\mathbf{0}$ & $\mathbf{3 1 8} / \mathbf{5 8 8}$ & $\mathbf{5 4 \%}$ & $\mathbf{7 4 / 1 4 1}$ & $\mathbf{5 2 \%}$ \\
\hline
\end{tabular}

Fonte: Elaboração própria.

Destaca-se na Tabela 10 que a ocorrência do padrão oxítono nos numerais sixteen, nineteen, thirteen e fifteen foi bastante baixa e que a aplicação do padrão paroxítono foi alta em todas essas palavras. Observa-se que boa parte dos casos em que o padrão paroxítono foi aplicado nessas palavras não foram casos de retração, o que revela uma tendência de os falantes brasileiros aplicarem o padrão paroxítono nessas palavras tanto em contexto isolado quanto inseridas em frases. O mesmo pode ser observado no numeral seventeen, que foi produzido de maneira oxítona em apenas 4 casos e de maneira proparoxítona em 54 casos, dos quais apenas 30 foram casos de retração.

A última variável linguística considerada na análise da regra de retração de acento foi Pausa - cf. Tabela 11. Se compararmos a aplicação da retração nos casos com pausa e sem pausa a diferença não é muito significativa. Entretanto, se observarmos a aplicação da retração nos casos de pausa em comparação com os casos em que não houve retração, essa diferença é bastante significativa.

Tabela 11 - Retração de Acento em casos de Pausa - Inglês como L2

\begin{tabular}{ccccc}
\hline \multirow{2}{*}{ Pausa } & \multicolumn{2}{c}{ Retração } & \multicolumn{2}{c}{ Sem retração } \\
\cline { 2 - 5 } & $\mathbf{N}$ & $\mathbf{\%}$ & $\mathbf{N}$ & $\mathbf{\%}$ \\
\hline Com Pausa & 5 & $11,1 \%$ & 40 & $88,9 \%$ \\
Sem Pausa & 391 & $29,3 \%$ & 942 & $70,7 \%$ \\
\hline
\end{tabular}

Fonte: Elaboração própria. 
Observa-se que as ocorrências de pausa foram pouco numerosas, se considerarmos o total de dados obtidos nesta pesquisa (45/1378). Isso ocorreu porque, como mencionado, solicitamos que os informantes realizassem a leitura das frases de maneira natural e sem interrupções, de modo a evitar a influência de pausas sobre as sequências de choque acentual. Entretanto, sobretudo no nível básico, alguns informantes não conseguiram realizar a leitura das frases sem interrupções. Isso fica evidente nos resultados apresentados na Tabela 12, que apresenta as ocorrências de pausa e retração por nível de proficiência. Das 45 pausas, 39 ocorreram no nível básico, e a retração ocorreu em apenas 4 desses casos. As pausas são em uma quantidade significativamente menor nos níveis intermediário e avançado.

Tabela 12 - Cruzamento entre retração, pausa e nível de proficiência - Inglês como L2

\begin{tabular}{|c|c|c|c|c|}
\hline \multirow{3}{*}{$\begin{array}{c}\text { Nível de } \\
\text { Proficiência }\end{array}$} & \multicolumn{4}{|c|}{ Pausa } \\
\hline & \multicolumn{2}{|c|}{ Com Pausa } & \multicolumn{2}{|c|}{ Sem Pausa } \\
\hline & N/Total & $\%$ & N/Total & $\%$ \\
\hline Básico & $4 / 39$ & $10 \%$ & $76 / 419$ & $18 \%$ \\
\hline Intermediário & $0 / 5$ & 0 & $114 / 455$ & $25 \%$ \\
\hline Avançado & $1 / 1$ & $100 \%$ & $201 / 459$ & $44 \%$ \\
\hline TOTAL & $5 / 45$ & $11 \%$ & $391 / 1333$ & $29 \%$ \\
\hline
\end{tabular}

Fonte: Elaboração própria.

A variável Nível de Proficiência, como já mencionado, foi a primeira selecionada como estatisticamente relevante. Os resultados da Tabela 13 mostram que a aplicação da regra foi favorecida pelos falantes de nível avançado, enquanto que os falantes de nível intermediário apresentaram um peso relativo próximo do ponto neutro, e os informantes de nível básico, por fim, não favoreceram a aplicação da regra.

Tabela 13 - Retração de Acento por Nível de Proficiência - Inglês como L2

\begin{tabular}{cccccc}
\hline Nível de & \multicolumn{2}{c}{ Retração } & \multicolumn{2}{c}{ Sem retração } & \multirow{2}{*}{$\begin{array}{c}\text { PESO } \\
\text { Proficiência }\end{array}$} \\
\cline { 2 - 5 } & $\mathbf{N}$ & $\mathbf{\%}$ & $\mathbf{N}$ & $\mathbf{\%}$ & RELATIVO \\
\hline Básico & 80 & $17,5 \%$ & 378 & $82,5 \%$ & 0,34 \\
Intermediário & 114 & $24,8 \%$ & 346 & $75,2 \%$ & 0,45 \\
Avançado & 202 & $43,9 \%$ & 258 & $56,1 \%$ & 0,69 \\
\hline
\end{tabular}

Fonte: Elaboração própria.

Para verificar se a aplicação da retração nos contextos de frase sem choque acentual passa a ser mais frequente no decorrer do aprendizado, realizamos um cruzamento entre 
as variáveis Nível de Proficiência e Contexto. Podemos observar na Tabela 14 que a aplicação da retração é bem próxima nos dois contextos.

Tabela 14 - Retração de Acento por Contexto e Nível de Proficiência

\begin{tabular}{ccccc}
\hline \multirow{2}{*}{ Nível de Proficiência } & \multicolumn{3}{c}{ Contexto por Nível de Proficiência } \\
\cline { 2 - 5 } & \multicolumn{2}{c}{ Com Choque } & \multicolumn{2}{c}{ Sem Choque } \\
\cline { 2 - 5 } & $\mathbf{N}$ & $\mathbf{\%}$ & $\mathbf{N}$ & $\mathbf{\%}$ \\
\hline Básico & 42 & $20,4 \%$ & 38 & $20 \%$ \\
Intermediário & 57 & $27,7 \%$ & 57 & $30 \%$ \\
Avançado & 107 & $51,9 \%$ & 95 & $50 \%$ \\
\hline
\end{tabular}

Fonte: Elaboração própria.

\section{Discussão e Considerações Finais}

Iniciemos observando o que ocorre com os falantes nativos. Nossos resultados mostraram que a retração de acento ocorreu em 50,6\% dos casos, mas inclusive em sequências em que não havia choque entre dois acentos primários adjacentes. Essa taxa de aplicação da regra não é um resultado surpreendente, já que se trata de uma estratégia variável para a resolução de choques acentuais. Segundo Hayes (1989), acentos adjacentes são rigorosamente evitados no inglês e acentos próximos, mas não-adjacentes, tendem a ocorrer com menos rigor. Sendo assim, esperava-se que a retração fosse mais frequente nas frases com sequência de choque acentual, isto é, com dois acentos primários adjacentes, do que nas frases sem choque acentual, quando não havia encontro de dois acentos primários. Os resultados indicaram que a variável Contexto não foi estatisticamente significativa para a aplicação da regra pelos falantes nativos. Chama a atenção a diferença na proporção de aplicação da regra encontrada por Levey (1999) e neste trabalho. Enquanto em contextos com choque a autora encontrou $27 \%$, neste trabalho a aplicação foi da ordem de $49 \%$. Nos contextos sem choque, a aplicação em Levey foi de $12 \%$ contra $51 \%$ neste trabalho. Segundo a autora, o efeito do acento de pitch (pitch accent), que foi controlado em seu trabalho através da inserção de sequências com choque acentual em início de frase e em final de frase, pode ter influenciado o julgamento perceptual nesses dois contextos. Como na presente pesquisa todas as sequências (com choque acentual e sem choque acentual) foram inseridas na mesma posição prosódica e sintática nas frases, acreditamos que o acento de pitch não esteja influenciando nossos resultados.

Conforme mencionado, era previsto que a retração não ocorresse em palavras como complete [kəm' pli:t], pois, nesses casos, a primeira sílaba da palavra contém a vogal reduzida schwa [ə], que não poderia receber o acento e isso foi o que efetivamente ocorreu. 
Os resultados obtidos também indicaram que a única variável estatisticamente significativa para a aplicação da regra de retração de acento pelos falantes nativos foi Segmento Final. Observou-se que palavras terminadas em vogal longa (ex: bamboo) e em nasal (ex: thirteen) favoreceram a aplicação da regra, enquanto as terminadas em obstruinte (ex: retake) não favoreceram. Quando observamos a aplicação da retração por palavra, fica evidente que o fato de palavras terminadas em obstruinte terem desfavorecido a aplicação da regra está relacionado ao fato de as palavras grotesque, complete, discrete, police e express não terem apresentado nenhuma ocorrência de retração. Além da estrutura da sílaba final, percebe-se que essas palavras têm em comum o fato de a penúltima sílaba conter um schwa (no caso de $p$ [a]lice e c[a]mplete), um ditongo com schwa (gr[əo]tesque) ou a vogal curta e frouxa [I] (d[I]screte, [I]xpress). Apesar de não termos controlado estatisticamente o tipo de vogal na sílaba que receberia o acento no caso de retração, acreditamos que esse aspecto também pode ter influenciado os resultados encontrados nesta pesquisa, já que resultados semelhantes foram encontrados por Levey (1999), que não registrou nenhum caso de retração em palavras com o ditongo [əo] na sílaba que receberia o acento (ex: obese 'obeso').

Este trabalho tem como objetivo observar a aquisição de uma regra do inglês que é muito parecida no PB (exceto pela distância entre os choques de acento), de modo a se observar uma possível transferência positiva de L1 na aquisição de L2. No caso da regra de retração de acento, a transferência da regra da L1 teria um papel facilitador na aquisição da L2, já que a regra ocorre de maneira muito semelhante no português e no inglês. Os resultados referentes aos 30 falantes de inglês como L2 indicaram que a retração foi aplicada em $21,7 \%$ dos casos. Os resultados também mostraram que a retração passou a ser mais frequente conforme o avanço do nível de proficiência, ou seja, os falantes de nível avançado aplicaram mais retração de acento do que os falantes de nível básico e intermediário. Gayer e Collischonn (2007) encontraram a retração acentual em apenas $7 \%$ dos contextos com choque em PB, o que já aponta que a taxa de retração, mesmo nos níveis iniciais de aprendizado, é maior do que na língua materna. Observa-se que, no nível avançado, os falantes brasileiros apresentam uma taxa de retração muito aproximada à dos falantes nativos, conforme ilustra o Gráfico 1. 
Gráfico 1 - Retração de acento por nível de

proficiência e contexto - falantes nativos e L2

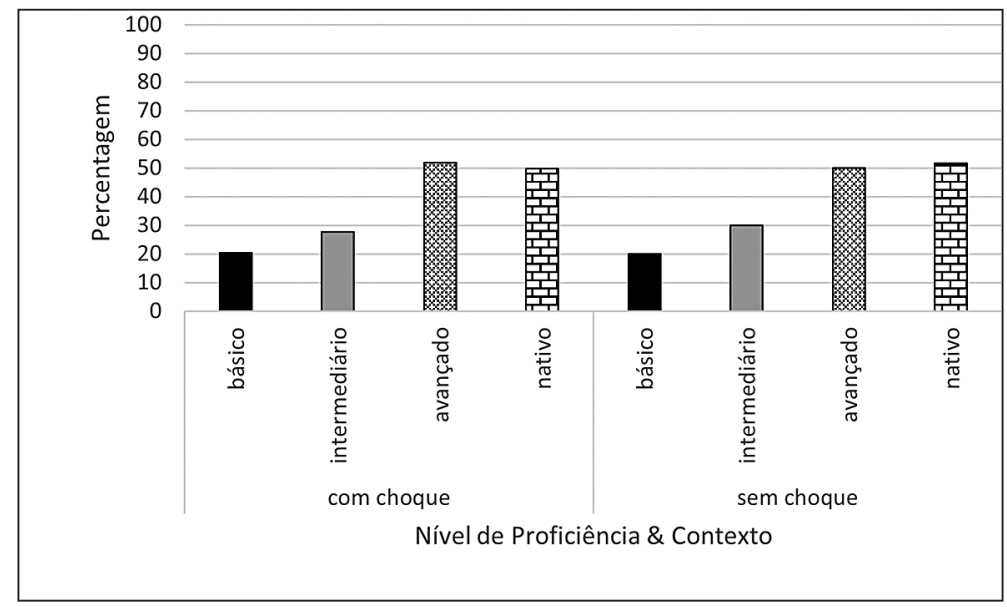

Fonte: Elaboração própria.

Como vimos, a regra de retração acentual no $\mathrm{PB}$ e no inglês é bem semelhante. De fato, o que se encontra é um menor contexto no PB, que só ocorre com acentos primários adjacentes. Assim, caberia aos falantes não-nativos aprender a aplicar a regra neste contexto em que não se aplica em PB. Neste caso, as taxas de aplicação deveriam ser maiores do que as encontradas: taxas parecidas nos contextos de choque e um aumento gradativo nas taxas de aplicação em contexto sem choque, conforme o nível de proficiência. Esse crescimento gradativo nos contextos sem choque é exatamente o que encontramos. No entanto, observa-se que as taxas são muito próximas daquelas dos contextos com choque - quando o esperado seria encontrar taxas maiores, já que o contexto da regra seria o mesmo nas duas línguas. Nossa interpretação é que a regra tenha sido pouco aplicada nos níveis iniciais porque esses informantes nem sempre são capazes de realizar a leitura das frases de modo natural, sem pausas, o que acaba bloqueando a aplicação da regra. Em outras palavras, dado que os informantes de nível básico ainda não são capazes de realizar a leitura das frases de forma fluente, é natural que tenham apresentado taxas de aplicação da retração de acento mais baixas do que os informantes dos níveis intermediário e avançado, já que a regra foi bloqueada pela leitura mais pausada e cautelosa característica deste nível. O fato de os falantes de nível básico terem apresentado uma taxa de retração de acento relativamente baixa não pode, portanto, ser usado como justificativa para afirmar que a L1 não estava operando no início da aquisição. Por outro lado, a aplicação em contextos sem choque por informantes do nível avançado aponta para a aquisição da regra do inglês, que é igual à do PB a não ser por esse fator da distância entre os acentos. 
Os resultados referentes aos falantes de inglês como L2 também mostraram que a única variável linguística estatisticamente relevante para a aplicação da regra foi Palavra Alvo. Assim como nos dados referentes aos falantes nativos, as palavras que contêm um schwa ( $p$ [a]lice), um ditongo com schwa (gr[əv]tesque) ou a vogal [I] ( $d[I]$ screte, [I]xpress) não favoreceram a retração. Conforme previsto, os casos de retração em palavras como police $(20 \%)$ e complete $(7 \%)$ indicam que os brasileiros podem ter produzido vogais plenas nas sílabas po- e com-, o que possibilitou a aplicação do acento paroxítono. Através do cruzamento entre Palavra Alvo e Segmento Final, percebemos que há uma tendência de palavras terminadas em vogal longa ou nasal serem mais favorecedoras para a retração do que as terminadas em obstruintes.

Em suma, observam-se muitas semelhanças entre os resultados dos falantes nativos e os falantes não nativos: 1) Do ponto de vista perceptual, a retração ocorre tanto em contexto com choque ou sem choque em proporções muito aproximadas; 2) A taxa de aplicação da retração pelos falantes de nível avançado foi bastante aproximada à taxa de aplicação dos falantes nativos; 3) Palavras terminadas em obstruinte não favorecem a aplicação da regra, enquanto palavras terminadas em vogal longa ou nasal favorecem.

Os resultados referentes à regra de retração de acento indicaram, portanto, diversas semelhanças entre os resultados dos falantes nativos e os falantes não nativos. Desse modo, consideramos que, sobretudo no nível avançado, a regra de retração de acento do inglês e todas as suas particularidades foi transferida do PB para o inglês.

FRAGOZO, C.; SANTOS, R. Acquisition of stress-shift in English by speakers of Brazilian Portuguese. Alfa, São Paulo, v.65, 2021.

- ABSTRACT: By addressing the acquisition of the English stress-shift rule by speakers of Brazilian Portuguese, this article sheds more light on the debate about the influence of first language and formal instruction on the acquisition of a second language. We carried out an experiment in which 37 native and non-native English speakers were asked to pronounce the same words as single words, in stress clash and non-stress clash contexts in order to observe the productivity of this phenomenon. The results show that stress shift occurs in similar proportions in contexts with and without stress clash and that productivity of the phenomenon among the advanced-level learners was very similar to that of the native speakers. We also found that words ending in an obstruent do not favor the application of the rule, whereas words ending in long vowels or nasals do. These findings show that syllable structure and the segmental inventory of the first language affect the results in the target language.

- KEYWORDS: Second language acquisition. Stress shift. English. Brazilian Portuguese. Phonological acquisition. 


\section{REFERÊNCIAS}

ABAURRE-GNERRE, M. B. Processos fonológicos segmentais como índices de padrões Prosódicos diversos nos estilos formal e casual do português do Brasil. Caderno de Estudos Lingüísticos, Campinas, n. 2, p. 23-34, 1981.

ABOUSALH, E. Resolução de choques de acento no português brasileiro: elementos para uma reflexão sobre a interface sintaxe/fonologia. 1997. 157f. Dissertação (Mestrado em Linguística) - Instituto de Estudos da Linguagem, Universidade Estadual de Campinas, Campinas, 1997.

BARBOSA, P. Explaining Brazilian Portuguese resistance to stress shift with a coupledoscillator model of speech rhythm production. Cadernos de Estudos Lingüísticos, Campinas, n. 43, p. 71-92, 2002.

BARBOSA, P. Syllable-timing in Brazilian Portuguese: uma crítica a Roy Major. D.E.L.T.A., São Paulo, v.16, n. 2, p. 369-402, 2000.

BOLINGER, D. Two kinds of vowels, two kinds of rhythm. Bloomington, IN: Indiana University Linguistics Club, 1986.

BROSELOW, E.; KANG, Y. Second language phonology and speech. In: HERSCHENSOHN, J.; YOUNG-SCHOLTEN, M. (ed.). The Cambridge Handbook of Second Language Acquisition. Cambridge, MA: Cambridge University Press, 2013. p.529-554.

CARROLL, J. B. The Carroll Model: A 25-Year Retrospective and Prospective View, Educational Researcher, Washington, v.18, n.1, p.26-31, 1989.

COOPER, W. E.; EADY, S. J. Metrical phonology in speech production. Journal of Memory and Language, New York, n.25, p.369-384, 1986.

CINTRA, G. Distribuição de padrões acentuais no vocábulo em português. Confluência, Assis, v. 5. n. 3, p. 83-92, 1997.

CORDER, S.P. The significance of learners' errors. International Review of Applied Linguistics in Language Teaching, Heidelberg, v.5, n.1/4, p.161-170, 1967.

COUNCIL OF EUROPE. Common European Framework of Reference for Languages: learning, teaching, assessment. Cambridge: Cambridge University Press, 2001.

ECKMAN, F. R. Markedness and the contrastive analysis hypothesis. Language Learning, Ann Arbor, v.27, p.315-330, 1977.

FERGUSON, C. Absence of copula and the notion of simplicity: A study of normal speech, baby talk, foreigner talk and pidgins. In: HYMES, D. (ed.). Pidgination 
and Creolization of Languages. Cambridge: Cambridge University Press, 1971. p. $141-150$.

FERREIRA, L. High initial tones and plateaux in Spanish and Brazilian Portuguese neutral declaratives: Consequences to the relevance of $\mathrm{F} 0$, duration and vowel quality as stress correlates. 2008. 187p. Thesis (Doctorate in Linguistics) - University of Illinois, Urbana-Champaign, 2008.

FLEGE, J. E. Second Language Speech Learning: Theory, findings, and problems. In: STRANGE, W. (ed.). Speech perception and linguistic experience: Issues in crosslanguage research. Timonium, MD: York Press, 1995. p. 233-277.

FRAGOZO, C. Aquisição de regras fonológicas do inglês por falantes de português brasileiro. 2017. 246f. Tese (Doutorado em Linguística) - Faculdade de Filosofia, Letras e Ciências Humanas, Universidade de São Paulo, São Paulo, 2017.

FRIES, C. C. Teaching and learning English as a foreign language. Ann Arbor: University of Michigan Press, 1945.

FRY, D.B. Experiments in the perception of stress. Language and Speech, Middlesex, n.1, p.126-152, 1958.

GASS, S. M.; SELINKER, L. Second Language Acquisition: An Introductory Course. 3.ed. Hillsdale, NJ: Lawrence Erlbaum Associates, 2008.

GAYER, J. E. L.; COLLISCHONN, G. Análise variacionista da resolução de choque de acento. Revista Virtual de Estudos da Linguagem - ReVEL, v.5, n. 9, ago. 2007.

GRABE, E.; WARREN, P. Stress Shift: Do Speakers Do It or Do Listeners Hear It? In: CONNELL, B.; ARVANITI, A. (ed.). Phonology and Phonetic Evidence. 1995. (Papers in Laboratory Phonology, IV). p.95-110.

HAYES, B. The prosodic hierarchy in meter. In: KIPARSKY, P.; YOUMANS, G. (ed.). Rhythm and Meter. Orlando: Academic Press, 1989. p.201-260.

HAYES, B. The Phonology of Rhythm in English. Linguistic Inquiry, Cambridge, v.15, n.1, p. 33-54, 1984.

KIMBALL, A.; COLE, J. Avoidance of Stress Clash in Perception of American English. In: SPEECH PROSODY, 7., 2014, Dublin. Proceedings [...], Dublin, Ireland, 2014. p. 497-501.

KRASHEN, S. D. Second Language Acquisition and Second Language Learning. Oxford: Pergamon Press, 1981.

LADO, R. Linguistics across cultures. Ann Arbor: University of Michigan Press, 1957.

LEVEY, S. The role of vowel quality in stress clash. 1999. 148f. Thesis (Doctorate in Linguistics) - University of New York, New York, 1999. 
LEVEY, S.; LAWRENCE, R. Stress clash: Frequency and strategies of resolution. Acoustical Society of America Journal, Melville, v.111, n.5, p. 2476-2476, 2002.

LEVIN, J.; FOX, J. A. Estatística para ciências humanas. 9. ed. São Paulo: Pearson; Prentice Hall, 2004.

LIBERMAN, M.; PRINCE, A. On stress and linguistic rhythm. Linguistic Inquiry, Cambridge, v. 8, n. 2, p. 249-336, 1977.

MADUREIRA, S. An acoustic study of sequences of words with adjacent primarystressed syllables: does stress shift occur in Brazilian Portuguese?. Cadernos de Estudos Lingüísticos, Campinas, v. 43, p. 109-126, 2002.

MAJOR, R. Foreign accent: The ontogeny and phylogeny of second language phonology. Mahwah, NJ: Lawrence Erlbaum Associates, 2001.

MAJOR, R. Stress and rhythm in Brazilian Portuguese. In: KOIKE, D. A.; MACEDO, D. P. (org.). Romance Linguistics: The Portuguese Context. Westport: London: Bergin Garvey, 1992. p. 3-30.

MASSINI, G. Acento e ritmo. São Paulo: Contexto, 1992.

MATTOS, A.M.A. A hipótese da gramática universal e a aquisição de segunda língua. Revista Estudos da Linguagem, Belo Horizonte, v.9, n.2, p.51-71, jul./dez. 2000.

MATTOSO CÂMARA Jr., J. Estrutura da Língua Portuguesa. Petrópolis: Vozes, 1972.

NESPOR, M.; VOGEL, I. Prosodic Phonology. Dordrecht: Foris Publications, 1986.

REETZ, H.; JONGMAN, A. Phonetics: transcription, production, acoustics and perception. Oxford: Wiley-Blackwell, 2009.

SÂNDALO, F.; TRUCKENBRODT, H. Some Notes on Phonological Phrasing in Brazilian Portuguese. In: CSIRMAZ, Z. et al. Phonological Answers (and their corresponding questions). 2002. (MIT Working Papers in Linguistics 42.). p.285-310.

SANTOS, R. Traces, pro and stress shift in Brazilian Portuguese. Journal of Portuguese Linguistics, Lisboa, v. 2, n. 2, p. 101-113, 2003.

SELINKER, L. Interlanguage. International Review of Applied Linguistics, Heidelberg, p.209-230, 1972.

SELKIRK, E. Phonology and Syntax: The Relation between Sound and Structure. Massachussetts: The MIT Press, 1984.

SILVA Jr, L. J. Interferências rítmicas do português no inglês como L2: o choque acentual. 2013. 223f. Tese (Doutorado em Linguística) - Universidade Federal da Paraíba, João Pessoa, 2013. 
STANDER, L. A aquisição do acento primário em inglês como LE: o caso das palavras sufixadas à luz da Teoria da Otimidade. 2007. 162f. Dissertação (Mestrado em Letras) - Universidade Católica de Pelotas, Pelotas, 2007.

TENANI, L. Fonologia prosódica. In: DA HORA, D.; MATZENAUER, C. (org.). Fonologia, fonologias: uma introdução. São Paulo: Contexto, 2017. p.109-123.

TRUBETZKOY, N. Princípios de Fonologia. Prague Linguistic Circle Papers, Praga, v.7, 1939.

WEINREICH, U. Languages in contact. New York: Linguistic Circle of New York, 1953.

Recebido em 01 de outubro de 2018

Aprovado em 02 de agosto de 2019 